\title{
Adaptive Control of a Non-Cylindrical Tank
}

\author{
http://dx.doi.org/10.3991/ijoe.v9i2.2546
}

\author{
C.R. Nippert, Rebecca Coburn, Brendon Shea, Michael Roth, Clinton Harrell, Edward Owusu \\ Widener University, Chester PA USA
}

\begin{abstract}
A conical tank in which the diameter changes with the tank height, allows the use of feedback control used in complex nonlinear systems, such as adaptive control. This project modified an existing system of two interacting tanks by inserting a removable solid cone into one of the tanks. This modification created two new nonlinear configurations, one of which had a discontinuity. Optimal controller settings at different depths of liquid were found by minimizing the integral of the absolute error (IAE). These settings were used by an adaptive PID controller at a different settings, comparing the results to a conventional PID tuned to that setting.
\end{abstract}

Index Terms-Adaptive control, nonlinear systems, process control, programmable logic controller

\section{INTRODUCTION}

Interacting tanks provide a useful model for the control of feed forward and feedback systems. Our existing system consisted of two interacting tanks. The first tank was fed by a centrifugal pump that pumped water from a 50 gallon sump to the tank. The flow was controlled by a pneumatically operated gate valve powered by a 0-15 psig signal driven by a 4-20 mA signal controlled from an Opto 22 Programmable Logic Controller (PLC). The first tank's discharge entered a second tank through a ball valve whose base is located $25.4 \mathrm{~cm}$ below the base of the first tank. The device measured liquid depth using air bubblers. Water returned to the sump from this second tank, by gravity, through a line in which the discharge can be controlled by another control valve operated by the same PLC. This equipment serves as an effective platform for teaching about conventional PID control (Figure 1).

The design challenge was to use this apparatus to create a nonlinear test apparatus that could be used for testing new process control algorithms, and still be easily converted back to its original configuration for conventional experiments in undergraduate laboratories. The department decided to make a system that would allow for experimentation with a nonlinear system such as a conical tank which has been used in research elsewhere (1).

The existing apparatus was modified using a solid, removable, conically shaped insert that can be easily lowered into the second tank using a pulley arrangement. There was also a change in the feed lines so that either tank can receive feed water from the pump. Changing configurations can be done in less than five minutes.

\section{DESIGN MODIFICATIONS}

A schematic of the modified process (with the cone inserted) is shown in Figure 2. Two different configurations are possible depending upon whether or not the connecting valve between the first and second tanks is opened (the manual valve below Tank 1 in Figure 2). The nonlinearity is shown in Figure 3 in the plot of tank volume vs. height (the red line in the figure). The discontinuity (blue line) occurs when the valve between the tanks is opened and when the water in tank 2 fills both tanks when the level in tank two exceeds $25.4 \mathrm{~cm}$

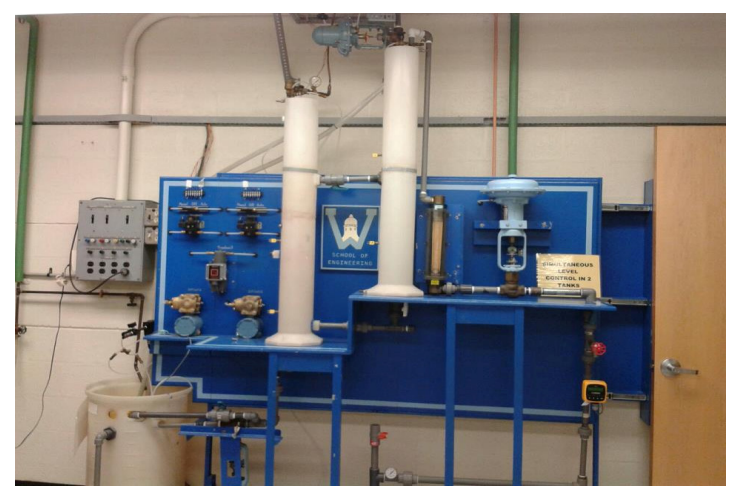

Figure 1. Initial system of two interacting tanks

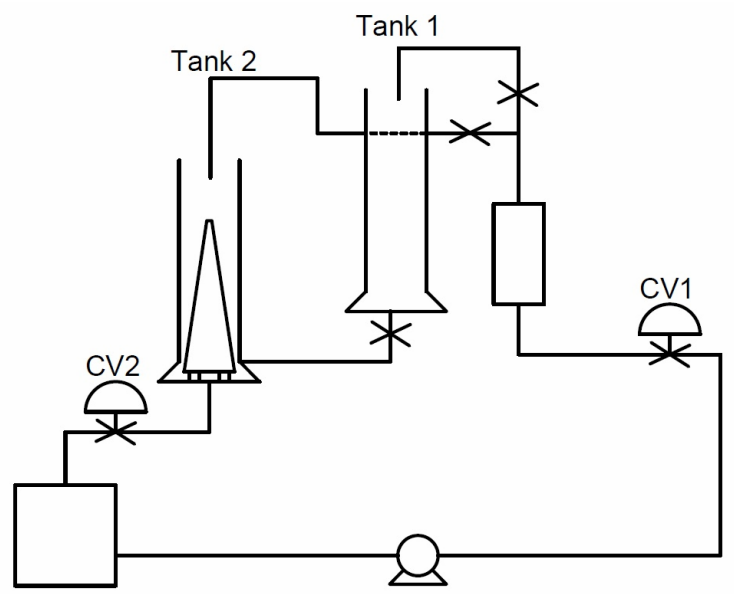

Figure 2. Schematic of two-tank apparatus

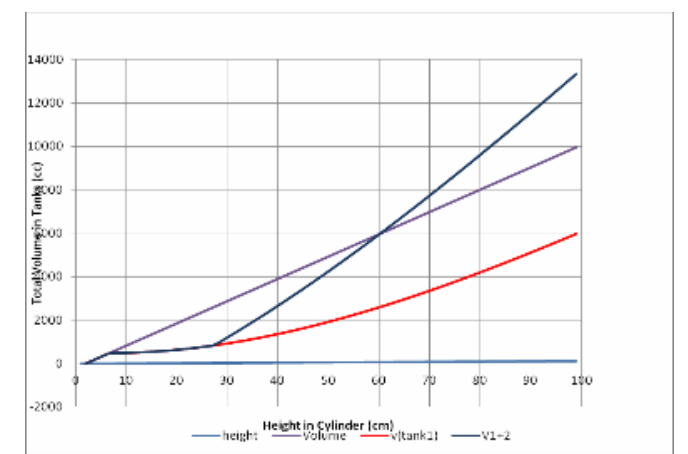

Figure 3. Volume of tank vs. Height of liquid in tank showing nonlinear behavior 


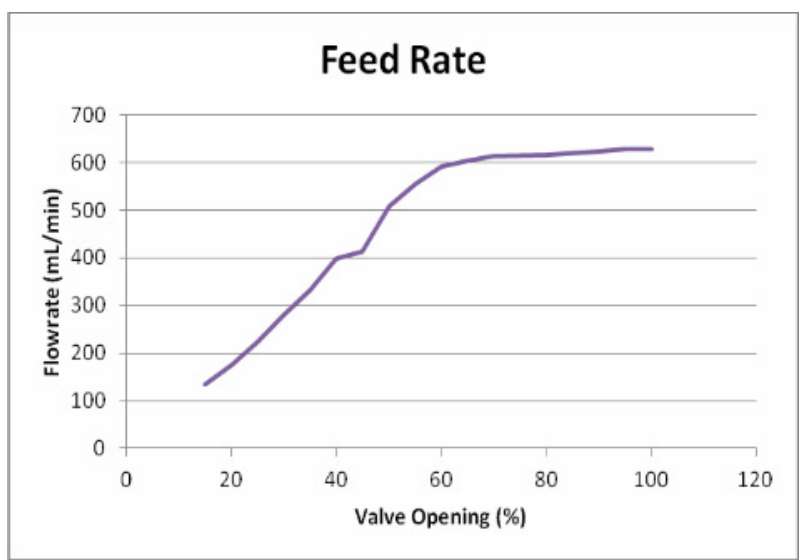

Figure 4. Calibration of flow in valve on entrance stream

The feed rate was measured at the entrance (CV1 in Figure 2). The results show the flow rate is fairly linear over the region between the valve being $20 \%$ and $60 \%$ open with saturation occurring at approximately $60 \%$ open. This region illustrates the operating range for the valve.

The nonlinear system can be used to test the behavior of a variety of controllers. For this project, focus was on the use of an adaptive PID controller that used PID settings at two different depths as the basis for control. The controller calculated the settings for all other depths from these 2 settings. Using an adaptive controller to run a nonlinear system is common, and offers potential savings over traditional PID control for a nonlinear process. This is where the use of an adaptive controller needs to be adjusted and changed to the correct settings of the noncylindrical tank.

\section{MATHEMATICAL DESCRIPTION OF THE NONLINEAR SYSTEM}

The change in the volume of water in the tanks is determined by a mass balance:

$$
\rho \frac{\mathrm{dV}}{\mathrm{dt}}=\rho \mathrm{F}_{\mathrm{in}}-\mathrm{k} \sqrt{\mathrm{h}+\Delta \mathrm{h}}
$$

Where $\rho=$ the density of water

$F_{\text {in }}=$ the volumetric flow rate in from the pump and the inlet valve

$h=$ the height of the water in the tank measured from the base of the tank

$\Delta \mathrm{h}=$ the vertical distance from the base of the tank to the mouth of the discharge

$\mathrm{k}=\mathrm{a}$ constant (a function of the signal to the valve, etc)

$\mathrm{V}=$ the volume of water in the tank

The volume of the tank occupied by water is the volume of the cylindrical tank minus the volume occupied by the solid cone (the total volume of the cone minus the volume of the cone above water).

$$
\mathrm{V}=\pi \mathrm{R}^{2} \mathrm{~h}+\left(\frac{1}{3}\right) \pi \mathrm{R}_{\mathrm{c}}^{2} \mathrm{~h}_{\mathrm{c}}-\left(\frac{1}{3}\right) \pi \mathrm{R}_{\mathrm{w}}^{2} \mathrm{~h}_{\mathrm{w}}
$$

Where $\mathrm{h}=$ the height of liquid in the tank measured from the base of the cone

$\mathrm{h}_{\mathrm{c}}=$ the height of the solid conical section inserted $(91.4 \mathrm{~cm})$ $h_{w}=$ the exposed height of the portion of the cone above water $\mathrm{h}_{\mathrm{w}}=\mathrm{h}_{\mathrm{c}}-\mathrm{h}$

$\mathrm{R}=$ the radius of the cylindrical tank

$\mathrm{R}_{\mathrm{c}}=$ the radius of the base of the cone $(5.1 \mathrm{~cm})$

$\mathrm{R}_{\mathrm{w}}=$ the radius of the exposed portion of the cone at the air = water interface $\mathrm{R}_{\mathrm{w}}=\mathrm{R}_{\mathrm{c}}\left(\frac{\mathrm{h}_{\mathrm{c}}-\mathrm{h}}{\mathrm{h}_{\mathrm{c}}}\right)$

After manipulation, the differential equation that describes the change in height of liquid as a function of time becomes the nonlinear differential equation on $\mathrm{h}$ :

$$
\frac{\mathrm{dh}}{\mathrm{dt}}=\frac{\rho \mathrm{F}_{\text {in }}-\mathrm{k} \sqrt{\mathrm{h}+\Delta \mathrm{h}}}{\pi \mathrm{R}^{2}+\pi\left[\frac{\mathrm{R}_{\mathrm{c}}}{\mathrm{h}_{\mathrm{c}}}\left(\mathrm{h}_{\mathrm{c}}-\mathrm{h}\right)\right]^{2}}
$$

After the modification to the equipment, the material balance yields the mass balance yields Equation 3 which describes the relationship between tank height and inlet flow.

\section{Determining CONTROLler SetTings}

The values for the P, I and D settings were determined experimentally to obtain the lowest IAE in response to a step change in the set point following the tuning method of Marlin(2). The IAE is defined in Equation 4.

$$
\mathrm{IAE}=\int_{0}^{\mathrm{t}^{\prime}} \mathrm{h}-\mathrm{h}_{\mathrm{set}} \mid \mathrm{dt}
$$

Where $\mathrm{h}=$ the height of water in the tank

$\mathrm{h}_{\text {set }}=$ the set point

$\mathrm{IAE}=$ the value of the absolute error

$\mathrm{t}=$ time

$\mathrm{t}^{\prime}$ = the time for the signal to achieve the new set point

Figure 5 shows the IAE graphically as the area between the experimentally measured height and the set point. In Figure 6, the red line shows the set points and the blue line shows the actual height. The integral of the absolute error is the area between these lines.

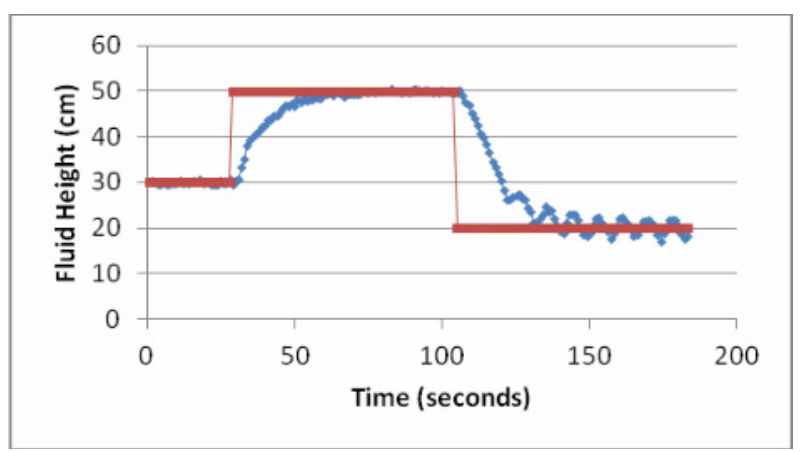

Figure 5. Response of System with One P, I, and D setting

The experimental testing included determining the PID settings at three separate tank heights; 20,40 , and $60 \mathrm{~cm}$. Once the set point was configured, the adaptive PID controller could be run.

The OPTO LCSX software determined the IAE in response to adjusting the set point. There were two adjustments for each set of PID settings. First the set point was 
changed from a steady state to a new set point and second, the set point was returned to its original set point. The optimum tuning settings are summarized in the following tables. The values of the P, I, and D settings were changed until the minimum IAE was found and was repeated at the levels of 20,40, and $60 \mathrm{~cm}$ to determine each of the optimal P, I, and D settings. Once these results were found, the optimal settings at the 20 and $60 \mathrm{~cm}$ were used in the adaptive controller. The level at $40 \mathrm{~cm}$ was tested with this adaptive controller, and compared to its optimal IAE values.

\section{SUMMARY OF RESULTS}

Shown in Tables 1-3 are the P, I, and D values that resulted in the lowest IAE. Three different sets were taken one at each fluid height of 20,40, and $60 \mathrm{~cm}$. These settings were determined with the solid cone inserted and using only Tank 2.

Note that the results shown in Table 4 indicate that the adaptive controller, which were a linear fit of the settings from the two headings, were not as good as the optimal settings shown on Table 2.

The results give the data that was found from the OPTO LCSX software. The optimal settings were determined by having the combined lowest values for the IAE without having any instability in the system. These values were then able to be used in the adaptive controller. The adaptive controller was set at the inlet valve with the optimal settings shown in Tables 1 and 3.

Last 4 rows in Table 4 show the results of the adaptive controller with the discontinuity in volume caused by opening the valve between the two tanks. Notice that controlling the height at the discontinuity produces a significantly larger IAE than when the discontinuity is absent.

\section{CONCLUSION}

The initial settings for the P, I, and D were found by minimizing the IAE at three points: two extreme values and a value in the middle (near the point of inflection on Figure 3). These settings were used to maintain a level at this value using an adaptive control algorithm. The adaptive control gave an IAE that was less effective than optimal tuning settings experimentally determined for this value. The presence of the discontinuity for certain configurations gave an increase in the IAE but still allowed for adequate control. This process allowed for testing of nonlinear systems (as indicated by the range of PID settings determined at various heights); making this a suitable apparatus.

\section{REFERENCES}

[1] N.S. Bhuvaneswari,* G. Uma,** and T.R. Rangaswam, "Neuro Based Model Reference Adaptive Control of a Conical Tank Level Process", Control and Intelligent Systems, Vol. 36, No. 1 2008, pp. 98- 105 http://dx.doi.org/10.2316/Journal.201.2008.1.201$\underline{1895}$

[2] R Ciancone and T Marlin, Tune controllers to meet plant objectives, Control, $\mathbf{5}$,
TABLE 1

OPTIMAL P, I AND D SETTINGS BASED ON CHANGING SET POINTS FROM 20-30CM

\begin{tabular}{|c|c|c|c|c|c|c|}
\hline Initial & \multirow{2}{*}{ Final } & \multicolumn{5}{|c|}{ Settings } \\
\cline { 3 - 6 } & & $\boldsymbol{P}$ & $\boldsymbol{I}$ & $\boldsymbol{D}$ & $\boldsymbol{I A E}$ & $\begin{array}{c}\text { Total } \\
\text { IAE }\end{array}$ \\
\hline 20 & 30 & 9 & 4.5 & 0.1 & 44.6 & \multirow{2}{*}{90.6} \\
\hline 30 & 20 & 9 & 4.5 & 0.1 & 46 & \\
\hline
\end{tabular}

TABLE 2

OPTIMAL P, I AND D SETTINGS BASED ON CHANGING SET POINTS FROM 35-45 CM

\begin{tabular}{|c|c|c|c|c|c|c|}
\hline \multirow{2}{*}{$\begin{array}{c}\text { Initial } \\
\text { Set } \\
\text { Point }\end{array}$} & \multirow{2}{*}{$\begin{array}{c}\text { Final } \\
\text { Set } \\
\text { Point }\end{array}$} & \multicolumn{5}{|c|}{ Settings } \\
\hline & & $\boldsymbol{P}$ & $I$ & $D$ & $I A E$ & $\begin{array}{l}\text { Total } \\
\text { IAE }\end{array}$ \\
\hline 35 & 45 & 6 & 4. & 0.1 & 34.5 & \\
\hline 45 & 35 & 6 & 4. & 0.1 & 40 & 4.5 \\
\hline
\end{tabular}

TABLE 3

OPTIMAL P, I AND D SETTINGS BASED ON CHANGING SET POINTS FROM 50-60 CM

\begin{tabular}{|c|c|c|c|c|c|c|}
\hline \multirow{2}{*}{$\begin{array}{c}\text { Initial } \\
\text { Set } \\
\text { Point }\end{array}$} & \multirow{2}{*}{$\begin{array}{l}\text { Final } \\
\text { Set } \\
\text { Point }\end{array}$} & \multicolumn{5}{|c|}{ Settings } \\
\hline & & $\boldsymbol{P}$ & $I$ & $D$ & $I A E$ & $\begin{array}{l}\text { Total } \\
\text { IAE }\end{array}$ \\
\hline 50 & 60 & 7 & 43.5 & 0 & 35.4 & \\
\hline 60 & 50 & 7 & 3.5. & 0 & 39.6 & 73 \\
\hline
\end{tabular}

TABLE 4

OPTIMAL P, I AND D SETTINGS COMPARED TO ADAPTIVE CONTROLLER OPERATION

\begin{tabular}{|c|c|c|c|c|c|c|}
\hline Initial & Final & \multicolumn{5}{|c|}{ Settings } \\
\cline { 3 - 6 } $\begin{array}{c}\text { Set } \\
\text { Point }\end{array}$ & $\begin{array}{c}\text { Set } \\
\text { Point }\end{array}$ & $\boldsymbol{P}$ & $\boldsymbol{I}$ & $\boldsymbol{D}$ & \multirow{I}{*}{$\boldsymbol{I} \boldsymbol{E}$} & $\begin{array}{c}\text { Total } \\
\text { IAE }\end{array}$ \\
\hline 35 & 45 & $\mathrm{~A}$ & $\mathrm{~A}$ & $\mathrm{~A}$ & 48 & \multirow{2}{*}{119} \\
\hline 45 & 25 & $\mathrm{~A}$ & $\mathrm{~A}$ & $\mathrm{~A}$ & 71 & \\
\hline 35 & 45 & $\mathrm{~A}$ & $\mathrm{~A}$ & $\mathrm{~A}$ & 43.5 & \multirow{2}{*}{112} \\
\hline 45 & 35 & $\mathrm{~A}$ & $\mathrm{~A}$ & $\mathrm{~A}$ & 68.5 & \\
\hline 35 & 45 & 9 & 4.5 & 0.1 & 43.8 & \multirow{2}{*}{132.9} \\
\hline 45 & 35 & 9 & 4.5 & 0.1 & 89.1 & \\
\hline 35 & 45 & 7 & 3.5 & 0 & 50.8 & \multirow{2}{*}{159.5} \\
\hline 45 & 35 & 7 & 3.5 & 0 & 108.7 & \\
\hline
\end{tabular}

A* Adaptive controller turned on and settings determined by controller

\section{AUTHORS}

C.R. Nippert is Associate Professor and Chair of the Department of Chemical Engineering at Widener University, Chester PA (email: crnippert@mail.widener.edu)

Rebecca Coburn, Brendon Shea, Michael Roth, Clinton Harrell, and Edward Owusu are Senior Engineering students at Widener University in the Department of Chemical Engineering at Widener University in Chester PA

Manuscript received 25 February 2013. Published as resubmitted by the authors 25 April 2013. 